\title{
Buda: un personaje para la historia del antiguo oriente
}

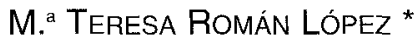

\section{EL MARCO HISTÓRICO}

La historia primitiva india surge como un lento amanecer que se va iluminando progresivamente. El primer destello pertenece al siglo $\mathrm{VI}$ a. de C., pues sólo en esta época alcanzan una dimensión histórica los procesos políticos al confrontarlos con las fuentes nuevas, las jainistas ${ }^{\top}$ y las budistas principalmente.

Los monarcas y dirigentes militares dejan de tener esa condición sobrenatural, por sus gestas guerreras, y se transforman en personajes históricos. Hasta el siglo vi sólo podemos establecer la historia india de modo global; realmente, desde los tiempos de las culturas del Indo, tal historia fue una serie de eslabones ininterrumpidos de luchas y creaciones culturales, batallas y disputas por el poder. Para nosotros constituye el siglo vi a. de C. un paréntesis de gran envergadura.

El siglo vı a. de C. es el de Shākyamuni ${ }^{2}$ que vivió alrededor del 556 al 476 a. de $\mathrm{C}$. El entorno que le rodea está organizado territorialmente en repúblicas y monarquías. En general, las repúblicas ocupaban las colinas y estribaciones montañosas situadas al sur del Himalaya, mientras las monarquías se asentaban en los terrenos llanos y más fértiles del valle del Ganges.

La tierra escenario de las vicisitudes de la vida del Buda, se extiende por el noroeste de la India, hacia el curso inferior y medio del río Ganges,

\footnotetext{
Departamento de Filosofía Moral y Política. UNED.

El nombre Shākyamuni es utilizado frecuentemente en unión con Buda (Buda Shākyamuni) en orden a distinguir el Buda histórico de otros Budas, cf. ROMÁN LóPEZ, 1994.

2 El jainismo es una religión india no ortodoxa, en cuanto rechaza la tradición de los Vedas. El fundador de la comunidad religiosa jaina, fue Mahāvira.
} 
entre el Himalaya al norte y los montes Vindhya al sur. Es, por consiguiente, una región extraordinariamente amplia.

En el ángulo que forman los ríos Son y Ganges estaba situado el reino de India Septentrional, Magadha, que al sur limitaba con la meseta de Chota Nāgpur y, a oriente, con el reino de Anga.

En el reino de Magadha gobernaba el rey Bimbisāra que había subido al trono en el 544 a. de C. y ampliado su reino conquistando el de Anga, en tanto aplicaba una política de acercamiento al más poderoso y temible reino de Kosala, tomando por mujeres a una princesa, hermana del rey de Kosala y a una noble de la potente confederación de los licchavi. Las fuentes budistas celebran a Bimbisāra como protector del budismo y verdadero amigo de Shākyamuni. Como monarca, el citado rey parece haber sostenido firmemente las riendas del poder: se preocupó de modo activo de la administración de su reino; llevó a cabo viajes de reconocimiento y supervisó las obras públicas. A Bimbisāra le sucedió su hijo Ajātasatru.

Al sur del río Ganges se extendía el reino de los vastsa y, más al sur todavía, el de Avantos. Al norte del Ganges había un grupo de estados republicanos que llegaban al Nepal y, después, a las montañas del Himalaya, agrupados en confederaciones; las más importantes de éstas eran: la de los malla y los shākya; y la de los vajii, formada por ocho repúblicas entre las que la mayor era la de los licchavi.

De un noble del orgulloso y guerrero clan de los shākya nació -en una fecha que de modo no muy preciso puede situarse hacia el 556 a. de C. - el personaje que conocemos con el nombre de Siddhārta Gautama el Buda, vocablo este último que significa «el iluminado». Sería también conocido más tarde como Shākyamuni («el asceta silencioso de los Shākya»), Tathāgata ("el así ido o llegado perfecto») y Baghavat ("el bienaventurado»).

También conocemos en parte la situación social de ese período. La mayor parte de la población pertenecía al campesinado: una agricultura moderadamente desarrollada, dotada de intrincadas técnicas de irrigación, había conquistado grandes territorios a los bosques. La rica producción agrícola, junto con la cría de ganado y los frutos de la pesca y la caza, alejaba el espectro del hambre. En general la vida diaria se desenvolvía en medio de una cierta tranquilidad.

El número de artesanos había aumentado y su producción era transportada por tierra y en barca por el Ganges por los mercaderes. Así, la cerámica negra pulida del norte se halla en zonas del Decán, muy alejados de su lugar de producción. La introducción de monedas acuñadas, de 
plata y cobre, posibilitó en gran medida el desarrollo comercial. Al mismo tiempo la concentración de comerciantes y artesanos en ciertas localidades llevó a la aparición y desarrollo de las primeras ciudades, como Taksasilā, en el noroeste o Rajagriha, situada al suroeste de Patna, junto al Ganges, entre otras.

En esta época, la casta de los brahmanes no había conseguido aún el lugar de exagerado privilegio espiritual y social que habría de conseguir más tarde.

La ciencia religiosa secreta, cuyo conocimiento es acaparado por los brahmanes, y que se formula mediante intrincadas y costosas prácticas de sacrificios, tiende a ser depreciada o satirizada. Sin embargo, la evolución y la expansión de un pensamiento filosófico que se identifica con un principio universal igual al espíritu individual, con el «sí mismo», dan un gran valor a la investigación personal en materia religiosa. El momento en que nace el Buda es, de hecho, de un gran y variado fervor espiritual.

Muchos «buscadores de la verdad», deambulantes se emplean a fondo en el descubrimiento de ese "sí mismo» a través de ejercicios de privación e introspección, extremando las carencias del cuerpo con el objeto de poner de relieve la fuerza del espíritu: casi paradójicamente hallan simpatizantes principalmente entre jóvenes de las aristocráticas y acaudaladas familias, a los que la sociedad hedonista, ligada a una cuidadosa y atrayente formación cultural, les hace percibir profundamente la necesidad de una nueva fe tras la desintegración de la antigua y la pérdida de significado de sus formas externas tradicionales.

\section{BIOGRAFIA DEL BUDA}

Las noticias sobre la vida y el pensamiento del Buda nos llegan a través de una colección de libros, agrupados en dos grandes tradiciones: el denominado "Canon septentrional», redactado en sánscrito, y cuyo origen se halla en el noreste de la India; y el "Canon meridional», que se usó en el sur de la India y está escrito en pāli ${ }^{3}$.

En líneas generales, el Canon pāli es el que refleja más de cerca el pensamiento del Buda y de sus inmediatos discípulos. Se trata de una colección vastísima conocida con el nombre de Tripitaka («Tres cestas»).

3 Dialecto indio, derivado del sánscrito. 
Se indican así las tres divisiones en que el Canon pāli está ordenado: el Vinaya-pitaka (reglas de orden, preceptos), el Abhidharma-pitaka (tratados, comentarios) y el Sütra-pitaka (discursos doctrinales del Buda).

Estos textos fueron transmitidos de modo oral y por eso no es raro que en ellos se hayan interpolado exageraciones de toda índole, y que se hallen versiones distintas de un mismo evento, asi como constantes reiteraciones. En realidad, en los relatos más antiguos asistimos con frecuencia al interrogatorio del Buda a sus discípulos sobre algunos puntos de su pasado. Si bien de esta imponente colección de obras resulta con todo viable sacar información para una biografía del Buda, menos fácil es discernir entre historia y leyenda. Una gran cantidad de eventos que alli se relatan son de carácter prodigioso e implican conductas sobrenaturales, cuando en sus comienzos debieron ser plenamente normales y posiblemente mostrasen la realidad histórica. Por otro lado, los libros del Canon pāli ponen más atención en los acontecimientos históricos, sociales y políticos que la que es habitual en los antiguos textos indios; a ellos les debemos un importante conocimiento de las estructuras políticas y de la vida cotidiana de los siglos $\vee$ y $\vee$ a. de $C$.

Sin embargo, en la literatura del Canon pāli no encontramos una verdadera biografía del Buda ${ }^{4}$; existen, eso sí, numerosos sucesos aislados, a menudo bastante pormenorizados, pero de arduo ordenamiento cronológico. En ellos se concreta cuidadosamente dónde y hacia quién el Buda llevó a cabo determinados actos o dijo determinadas palabras, pero rara vez cuándo lo hizo.

En general, poseemos una amplia información acerca de los años de juventud de Shākyamuni; lo podemos seguir casi paso a paso en los meses del comienzo de su predicación; hay luego un importante período de casi cuarenta años, en el que carecemos de datos cronológicos exactos, mientras que en el último período de su vida $-\mathrm{y}$ sobre todo los

\footnotetext{
4 El origen de la biografía del Buda que poseemos se halla, en primer lugar, en el mismo Canon budista, en el cual junto con la doctrina abundan naturalmente elementos informativos de la vida de Shākyamuni. Expresamente biográficos, el Lalitavistara relata la «maravillosa vida del Buda", narrada por él mismo a sus discípulos, en un estilo poético y fantástico; los Jatakas cuentan los «renacimientos" del Buda y sus existencias anteriores; también el Buddhavamsa narra la "genealogía del Buda", sus veinticuatro existencias anteriores y su vida, por boca de él mismo. Fuera del Canon, el poeta filósofo del siglo i a. de C., Ashvaghosha, nos ha dejado la biografía en verso, el Buddha-charita. La Luz de Asia (El Poema del Buda) de Edwin Arnold (Barcelona 1984) junto con El Evangelio de Buda de Pablo Carus (Barcelona 1978) son dos de las mejores biografías del Buda escritas por occidentales. Y finalmente la famosa novela de Herman Hesse, Siddhartha.
} 
momentos que precedieron a su muerte- nos es conocido de modo muy detallado ${ }^{5}$.

El personaje histórico del Buda se manifiesta a través de una espesa niebla de leyendas, fechas imprecisas y ningún escrito que se le pueda atribuir. En realidad sólo sabemos con certeza que fue un hombre que predicó una doctrina que se alejaba del hinduismo tradicional ${ }^{6}$ de su época, fundamentándose en las Cuatro Nobles Verdades acerca del sufrimiento y en el nirvāna como estado supremo que libera de la rueda de la existencia; que reunió a un considerable número de discípulos constituidos en vida monástica, y originó un gran movimiento denominado budismo.

El resto de las circunstancias, no se conocen con absoluta certeza histórica. No obstante vamos a exponer una síntesis de la biografía del Buda tal como la presentan algunos tratados budistas.

Se cuenta que el Buda Shākyamuni nació a mediados del siglo vı a. de C. en una aldea del Terai nepalés al pie de los primeros contrafuertes del Himalaya, en Kapilavastu. Era el heredero de la casa reinante de los Shākyas. Recibió el nombre de Siddhārtha («el que ha alcanzado su meta»). Aunque algunas leyendas presentan a su padre como un rey, lo más probable es que se tratara de un noble local, descendiente del clan brahmánico de los Gautama.

Cuando contaba con veintinueve años abandonó su hogar y su familia para vivir la extremada ascesis del monje errante en busca de un medio de salvación. Esta decisión tan drástica fue debida, según la tradición, a cuatro señales que en su vida de abundancia y lujo le indicaron la transitoriedad e impermanencia del mundo y de los hombres: la vejez, la enfermedad, la muerte y un monje errante.

5 Ver R.A. Ruy, El Libro de la Gran Extinción de Gotama el Buddha o sea el Mahā Parinibbāna Suttanta del Dỉgha Nikāya, Hachette, Buenos Aires, 1975.

6 A pesar de que existen muchos puntos en común entre el budismo y el hinduismo, también es cierto que hay una serie de aspectos donde divergen ambas tradiciones. En primer término, la carencia de texto revelado y de ritual externo del budismo frente a la aceptación de los Vedas como palabra revelada y la observación de sus ceremonias por el "Camino del Medio" propuesto por el budismo, entre los placeres de los sentidos y las mortificaciones rigurosas y el ascetismo como meta en sí mismo o como vía para la obtención de poderes, extravíos comunes en el hinduismo. La práctica inmediata de la vida ascética en el budismo, mientras que la literatura canónica hindú obliga previamente al desempeño de las obligaciones de estado sociales. La organizacion de los discípulos en comunidad monástica que, con sus adeptos laicos, constituyen la totalidad del budismo, por contra en el hinduismo, el monaquismo es tardío y parcial y los ascetas representan una excepción. El budismo prescinde de las castas. Pero donde ambas tradiciones difieren sobre todo es en su interpretación de la naturaleza del «yo». 
Durante unos años experimentó y rechazó la filosofía abstracta y el ascetismo físico radical. Posteriormente, en una noche de profunda meditación, alcanzó la iluminación.

Antes de producirse este acontecimiento, cuenta la tradición que tuvo una visión en la que vio sus numerosas vidas anteriores. Comprendió después que las alegrías y los sufrimientos que padecen los seres obedecen al valor moral de los actos que hayan realizado éstos en una existencia pasada. Por último, tras haber considerado la realidad del dolor inseparable de la vida y de sus circunstancias, la realidad del origen de este sufrimiento causado por el deseo, la realidad del cese de éste y la realidad del camino que conduce a esta liberación, se percató de pronto del hecho de que había traspasado las barreras del sufrimiento y de la angustia que afligen a los mortales. Después de ésto se llamó a sí mismo el Buda (el Iluminado). En adelante en el transcurso de un largo ministerio como predicador errante, enseñó las Cuatro Nobles Verdades y el Octuple Sendero. Formó una Comunidad que fueron engrosando discípulos mendicantes procedentes de todas las castas, mujeres y laicos devotos.

El Buda murió en Kushinagara a los ochenta años de edad, obteniendo - según narra la tradición- el parinirväna. Su cadáver fue incinerado y sus cenizas repartidas entre numerosos seguidores de distintas regiones, que las conservaron como reliquias en túmulos o stūpas construidos a tal efecto. Estos lugares se convertirían más tarde en centros de peregrinación para muchos devotos budistas.

\section{DESARROLLO DEL BUDISMO}

Tras la muerte del Buda, sus adeptos celebraron un primer concilio con el fin de ordenar y fijar toda su enseñanza frente a desacuerdos que ya empezaban a hacer su aparición. Aunque algunos eruditos occidentales dudan de la realidad de este primer concilio, parece que tuvo lugar poco tiempo después de la muerte del Buda en donde concurrieron unos quinientos monjes. Fue presidido por Mahākāshyapa. Ānanda recitó ante aquella congregación de monjes las palabras del Dharma, que constituirían los Sütras y Upāli expuso las reglas monásticas, Ilamadas Vinaya. Dada la imposibilidad de transcribir las recitaciones de Ananda y Upāli, fue necesario someter cada relato a un análisis crítico y la recitación grupal sólo se llevó a cabo con la aprobación unánime de los allí reunidos. De ahí que se llame a este concilio «la primera recopilación de los textos» o "la primera declamación grupal». Las primeras discrepancias surgieron ya en aquellos momentos debido, al parecer, a ciertas reservas 
expresadas por algunos monjes respecto a la codificación de la Enseñanza hecha por Mahākāsyapa y sus compañeros. Un segundo concilio cuya fecha precisa se desconoce, se congregó en Vaishāli con el fin de condenar diez prácticas prohibidas de un grupo de religiosos de la tribu de los Vajji. No es posible determinar con precisión la naturaleza de esas actividades; pero, al parecer, fueron lo suficientemente importantes como para crear una escisión de la comunidad. El Dipavamsa cingalés relata que, tras ser rechazadas por la asamblea allí reunida las propuestas de los monjes de la tribu de los Vajji, éstos se retiraron y convocaron un concilio por su cuenta, al que dieron el nombre de "Gran Recitación". Con el tiempo este grupo pasó a denominarse Mahāsānghika, para diferenciarlo de la escuela Theravāda. Y, de este modo, la Comunidad quedó escindida en dos bandos. El tercer concilio tuvo lugar a mediados del siglo III a. de C., bajo la iniciativa del rey Ashoka en la actual Patna. Se reafirmaron las doctrinas fundamentales y se condenaron y reformaron los excesos que habían penetrado en la vida monástica. Finalmente, el cuarto concilio reunido por Kanishka en el siglo । d. de C., tuvo lugar en Kashmir. Parece que había dieciocho sectas budistas en aquel momento. En este concilio quedó patentizada la separación de la comunidad budista en dos sectores, dentro de los que se puede agrupar el resto de las sectas que aparecieron posteriormente: Hīnayāna y Mahāyāna ? . (Cuadro 1).

La escuela Theravāda es la única que perdura, de forma que ella constituye desde hace mucho tiempo el «Pequeño Vehículo» (Hīnayāna), denominada también «Escuela del Sur» porque impera en Asia sudoriental (Birmania, Sri Lanka, Tailandia, Laos y Camboya). Su literatura de base constituye el Canon pāli, fijado alrededor del año 69 al 40 a. de C. en Sri Lanka.

En el transcurso de los siglos । a. de C. y I d. de C. tuvieron lugar en la India del norte dos importantes acontecimientos. En primer lugar, el surgimiento de una literatura marcadamente especulativa, que desarrollaba conceptos ya formulados por la escuela Theravāda o mantenidos por los grupos escindidos de ésta. Tal es el caso de la figura del Buda virtual (Bodhisattva) que supera a la del santo (arhat). En segundo lugar, el inicio de una actitud devocional-ritual, inexistente hasta ese momento, hacia los Budas y sobre todo hacia los bodhisattvas.

Véase E. Conze, Breve Historia del Budismo, Alianza Editorial, Madrid, 1983. D. IKEDA, Budismo primer milenio, Taurus, Madrid, 1988. 


\section{CUADRO 1}

\section{Escuelas Budistas}

| ORIGINARIAS
1. Pequeño Vehículo de Salvación (Hīnayāna)

2. Gran Vehículo de Salvación (Mahāyāna)
1. Sthaviravāda o Theravāda

2. Sarvāstivāda

3. Sautantrika

1. Vijn̄ānavāda

2. Mādyamika

3. Vajrayāna (Vehículo de diamante) Budismo tibetano: mezclado con elementos tántricos
II FORMAS CONTEMRÁNEAS
1. Escuelas del Pequeño Vehículo

2. Budismo Zen

3. Budismo Tibetano

4. «¿Budismo occidental?»

La literatura citada con anterioridad sin influir en la autoridad del Canon pāli conforma las líneas maestras de una nueva tendencia del budismo: el "Gran Vehículo" (Mahãyāna), también llamado, "Escuela del Norte». Esta última denominación se debe a que en un período de tiempo relativamente corto se había propagado sobre todo en el Norte de la India desde donde llegó al Tíbet, China y Japón.

La escuela Theravāda mantuvo su unidad mientras que el Mahāyāna se parceló en numerosas sectas; por ejemplo, tomó en el Tíbet, Nepal y 
Mongolia una estructura original, conocida como "lamaísmo" ${ }^{8}$. El budismo tibetano está subordinado directamente a una guía nueva que, originaria de la India del Norte, entró a formar parte del Mahāyāna: el tantrismo ${ }^{9}$.

En la antigüedad, los contactos del budismo con Occidente fueron imprecisos y escasos ${ }^{10}$. Fue en el siglo XVI cuando se intensifica el contacto entre oriente y occidente con el descubrimiento y colonización de aquellos países por los occidentales, el conocimiento de las religiones del Lejano Oriente se obtuvo sobre todo a través de las crónicas de los misioneros.

Sin embargo, la atracción de los eruditos occidentales por Oriente, en forma sistemática y profunda, comienza en el siglo pasado. Uno de los primeros en llamar la atención sobre el significado del Buda y su doctrina fue el filósofo Schopenhauer. Pero durante el segundo tercio del siglo XIX empezaron a aparecer investigaciones y traducciones sistemáticas sobre la enseñanza y las fuentes budistas. Aumentó el interés por las lenguas orientales y tras las primeras traducciones aisladas comenzó en 1880, bajo la dirección de Max Müller, la importante serie de traducciones al inglés: The Sacred Books of the East. Posteriormente, gracias a la iniciativa de Rhys Davids y su esposa, grandes admiradores del budismo, se creó la Päli Text Society en Londres. Mencionemos la Bibliotheca Buddhica de la Academia de Ciencias de San Petesburgo y las dos colecciones francesas Buddhica Memoires y Buddhica Documents, sólo por poner otros ejemplos importantes.

Ahora bien, si los estudios budistas han sido profundos, cuando pasamos a comprobar la «influencia» del mismo en la vida y en el pensamiento de Occidente no parece existir proporción de ésta con el interés teórico. Se han llevado a cabo innumerables ensayos por adaptar la vida budista en occidente, sobre todo en Estados Unidos y el Reino Unido. En este sentido, se creó la Buddhist Society en Londres por R.J. Jackson. Posteriormente Christmas Humphreys, dio a la Buddhist Society nueva vida y trató de dinamizar las relaciones entre los budistas.

Particularmente ha despertado interés el budismo tibetano y el Zen, sobre todo en Estados Unidos, a lo que ha contribuido la fecunda labor, en

8 Véase L. Austine WADDELL, The Buddhism of Tibet or Lamaism, Asian Education Services, New Delhi, 1991.

- Ver Jean Riviere, El Yoga Tántrico, Kier, Buenos Aires, 1978.

10 Cubre toda la historia, desde la antigüedad hasta nuestros dias la documentada obra de $\mathrm{H}$. de Lubac, La rencontre du Bouddhisme et de L'Occident, Aubier, París, 1952. 
el caso del zen, de D.T.Suzuki. El budismo tibetano, por su parte, ha salido de las limitadas fronteras del Tibet y sus enseñanzas secretas se están dando a conocer en Occidente. No obstante, la "práctica" del budismo y su incorporación como religión vivida en occidente no deja de ser minoritaria.

\section{LA DOCTRINA}

Sólo hay dos doctrinas que con cierta seguridad pueden ser atribuidas a la prédica inicial del Buda: la del origen condicionado de los seres y las Cuatro Verdades Nobles (Cuadro 2).

La doctrina del origen condicionado de los seres sirvió en un principio para explicar el ciclo de las existencias del hombre y luego se extendió a todo el mundo de los fenómenos. En su forma completa, prescindiendo de las variantes que a veces los textos ofrecen, la explicación señala, en el ciclo de las existencias del hombre, doce momentos, cada uno de los cuales está determinado por el anterior y es determinante del siguiente.

CUADRO 2

La doctrina de Buda

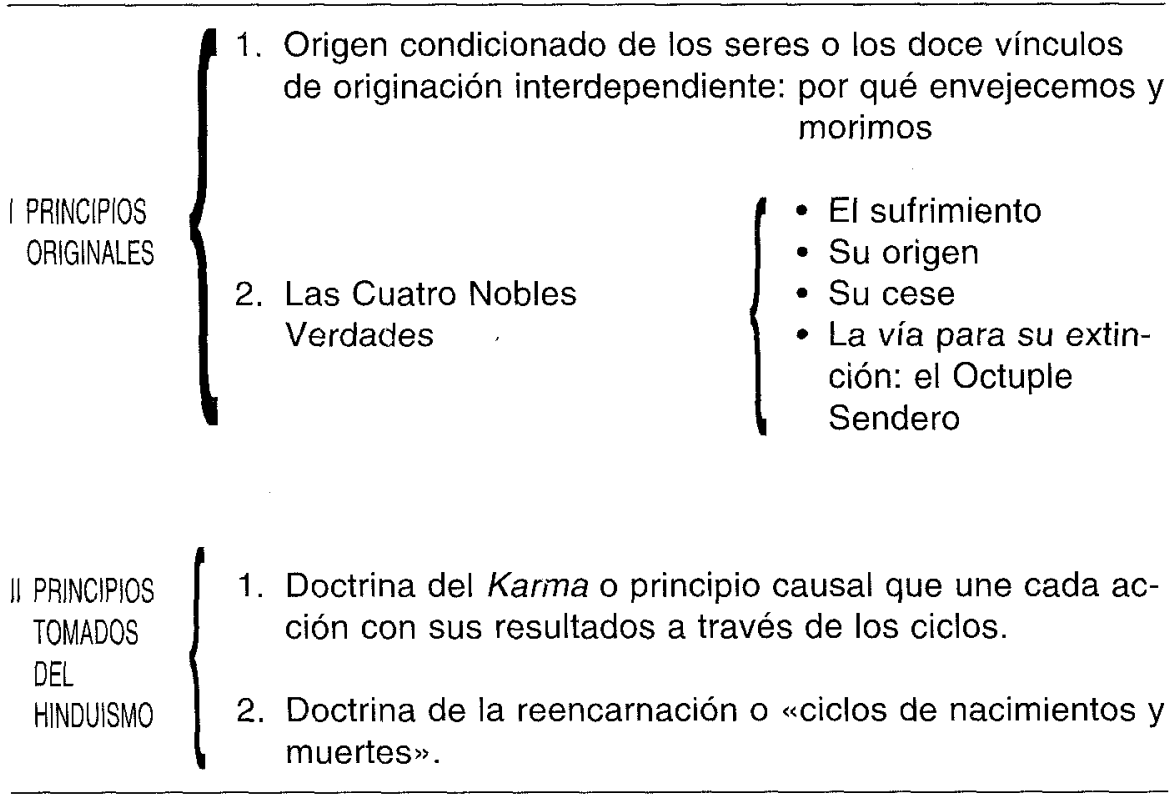


Estos doce eslabones de originación interdependiente ponen de relieve el proceso por el que permanecemos encadenados a un ciclo incontrolado de muertes y renacimientos junto con sus sufrimientos respectivos. La causa fundamental de este proceso incontrolado es el primer vínculo, la ignorancia. Bajo el dominio de la ignorancia llevamos a cabo actos positivos o negativos, que son la causa para el renacimiento en las esferas inferiores o superiores de la existencia cíclica ${ }^{11}$.

La segunda doctrina, es decir, las Cuatro Verdades Nobles, desarrolla una cuestión que para el pensamiento indio constituye una novedad en la perspectiva del mundo. En la literatura budista se señala que el Buda sólo pretende explicar el sufrimiento, el origen, la eliminación, y el camino que lleva a su erradicación.

El budismo, como todas las escuelas de la época, intenta ofrecer una vía para la eliminación del dolor. Para ello ofrece la fórmula de las Cuatro Verdades Nobles, que es común a las distintas escuelas indias de la época y a las posteriores, aún cuando una de ellas le dé un contenido y un sentido diferentes.

Las Cuatro Verdades Nobles aprehendidas por Shākyamuni mientras estuvo inmerso en profunda meditación, sentado bajo el árbol Bodhi en Gayā, fueron expuestas por él a los cinco ascetas, sus antiguos compañeros en la búsqueda de la verdad, cuando ofreció su primer sermón en el Parque de los Ciervos en Isipatana, cerca de la ciudad india de Benarés. Estas Cuatro Verdades Nobles, aceptadas por todas las escuelas budistas, configuran la quintaesencia de su enseñanza y son: 1) el sufrimiento; 2) su origen; 3) su cese y 4) el camino que lleva a su eliminación.

El método de exposición de las Cuatro Nobles Verdades utilizado por el Buda ha sido comparado al de un médico. En primer lugar diagnostica la enfermedad, después encuentra la causa que la provoca, luego medita sobre el cese y, finalmente aplica el remedio.

El sufrimiento es el daño; el deseo es la causa de la enfermedad; erradicando el deseo se cura el daño y se obtiene la curación.

El concepto de sufrimiento es la pieza fundamental de la doctrina budista. El Buda lo presenta del siguiente modo:

\footnotetext{
Véase Takeuchi YoshinoRI, The Heart of Buddhism, The Crossroad Publishing Company, New York, 1983, págs. 63-81. Geshe Lobsang TSULTRIM, El adiestramiento Mental y los Doce Vínculos de Originación Interdependiente, Dharma, Novelda (Alicante), 1985, págs. 68-83.
} 
«Ahora bien, monjes; he aquí la «Noble Verdad» acerca del sufrimiento:

- El nacimiento es sufrimiento.

- La unión con lo desagradable es sufrimiento.

- La separación de lo agradable es sufrimiento.

- La enfermedad es sufrimiento.

- La vejez es sufrimiento.

- La muerte es sufrimiento.

En suma, los cinco conjuntos que constituyen el ser son causa de sufrimiento. Esta es la primera de las "Cuatro Nobles Verdades", la que concierne al sufrimiento» ${ }^{2}$.

Sir Edwin Arnold ha plasmado la imagen del sufrimiento en su célebre poema, La Luz de Asia:

«Entonces exclamó, mientras su rostro levantado

Lucía en candente pasión de amor

Inexplicable y con el ardor de una esperanza

Sin límites e insaciable: ¡Oh, mundo de sufrimientos!

¡Oh, conocidos y desconocidos de nuestra carne común;

Apresados en esta red común de la muerte y el dolor,

y de la vida que nos ata! Yo veo, yo siento

la magnitud de la agonía terrenal,

La inutilidad de sus placeres, la burla

Sobre lo mejor, y la angustia de su mal,

Hasta que las alegrías terminan en dolores y la juventud en vejez.

Y el amor en pérdida y la vida en una muerte odiosa.

$Y$ la muerte en vidas desconocidas, que sujetan

A los hombres de nuevo a sus ruedas para rodar en círculo" ${ }^{13}$.

La Verdad Noble sobre el origen del sufrimiento se formula en el Primer Sermón del Buda con las siguientes palabras:

«Esta es, monjes, La «Noble Verdad» acerca del origen del sufrimiento. Es la sed, acompañada de codicia la que tiende a provocar el renacimiento; la que busca gratificaciones aquí y allí; la que, incansablemente, pretende saciar a través de los placeres sensuales su deseo vehemente de vida y no vida. Esta es la segunda de las "Cuatro Nobles Verdades", la que concierne al origen del sufrimiento" ${ }^{14}$.

Es el deseo, esa sed, que mostrándose de distintos modos, hacen surgir todas las formas de sufrimiento, así como el continuo vagabundeo de los seres en la rueda de la existencia. Sin embargo, el deseo no es la primera causa. Pues, dado que según la doctrina budista todo es

Samuel Wolpin, El Sutra de Benarés. Primer Sermón, Ibis, Barcelona, 1988, pág. 48.

13 Edwin AfNolo, La Luz de Asia. El poema del Buda, Teorema, Barcelona, 1984, págs. $70-$ 71.

14 Samuel WOLPIN, ob. cit., pág. 49 
interdependiente y relativo, es improbable que exista una primera causa. Todo fenómeno tiene una causa y es a su vez la causa de otro fenómeno: de este modo, dependiente y sucesivamente se pone en marcha el ciclo denominado Generación Condicionada.

Parece que estaría fuera del ámbito de lo razonable negar el hecho del sufrimiento, si bien no es tan sencillo entender cómo esa sed origina la existencia y el devenir continuados. Para comprender ésto, debemos examinar, aunque sea de forma breve, las doctrinas del karma y de la reencarnación.

El pensamiento budista contempla la teoría del karma como una ley natural alejada de la idea de justicia moral o de premio y castigo. Esta última opinión procede del concepto de un Dios juez que dicta sentencia y decide sobre la bondad y maldad de los actos del hombre. No es difícil entender ésto; sin embargo, según la doctrina del karma, la dificultad radica en pensar cómo los resultados de una acción volitiva pueden aparecer en una vida después de la muerte.

El hombre es un compuesto psico-físico de mente y materia, que no se detiene con la muerte; sino que prosigue incesante y continuamente. Es el flujo psíquico dinámico, conocido como sed, ansia o deseo y voluntad, lo que conforma la rueda kármica. Esta es la energía más poderosa conocida. Según el budismo, ésta no desaparece con la muerte, por el contrario continúa manifestándose bajo otra forma, provocando un nuevo renacimiento.

El proceso kármico es la energía que, a partir de los requisitos de una existencia actual, condiciona una vida futura en una interminable secuencia. En este proceso no hay nada permanente o inmutable que pueda pasar de una vida a otra. Consiste en una serie sin solución de continuidad, cambiando constantemente. Esta serie es sólo movimiento, y se parece a una llama que permanece encendida toda la noche: no es la misma llama, ni tampoco es el mismo sujeto, pero tampoco es diferente.

El último instante de pensamiento en esta existencia condiciona el primer instante de pensamiento de la vida siguiente que, en definitiva, es la continuación de la misma serie.

Mientras el hombre está atado a la vida debido a su ignorancia, su apego y sus ansias al ciclo de nacimientos y muertes (samsāra) continuará. Así lo expresa el Dhammapada: 
Larga es la noche para el que permanece en vela; largo es el camino para quien está cansado, larga es la serie de nacimientos y muertes para el insensato que desconoce la verdadera ley ${ }^{15}$.

Dado que el karma es el resultado de nuestras acciones, podemos partir esa larga cuerda. Es eliminando la ignorancia y la energía propulsora del deseo de existencia como finaliza la rueda de la existencia.

La Tercera Verdad Noble, el cese del dolor, es conocida como nirvāna. Se trata de un término sánscrito de etimología poco precisa; sirve para describir la condición inefable del Despierto y se opone a la rueda de las reencarnaciones (samsāra). En este sentido, el nirvāna es la extinción de todo aquello relacionado con el universo fenoménico y no parece susceptible de ser definido de forma positiva. Cuando intentamos definirlo utilizamos palabras que tienen significados concretos, mientras que el nirvāna estaría más allá de cualquier posible descripción.

La última Verdad Noble se refiere a la senda que conduce a la extinción del sufrimiento. Refiriéndose a esta vida, en su primer discurso, el Buda lo denominó Sendero Medio.

Este Sendero Medio es denominado generalmente Noble Sendero Octuple, porque consta de ocho ramales. Desde la perspectiva del entrenamiento práctico, las ocho divisiones se pueden escindir en tres grupos, que según Bikkhu Boddhi son:

1) El grupo de la disciplina moral (sillakkhanda), compuesto por la Recta Palabra, la Recta Acción y el Recto Sustentamiento; 2) el grupo de concentración (samādhikkhanda), compuesto por el Recto esfuerzo, la Recta Atención y la Recta Concentración, y 3) el grupo de sabiduría integrado por la Recta Opinión y el Recto Propósito. Estos tres grupos representan las fases del adiestramiento: el adiestramiento en la disciplina moral más eleva$\mathrm{da}$, el adiestramiento en la consciencia superior y el adiestramiento en la sabiduría más alta ${ }^{16}$.

El propósito de este óctuple ramal es perfeccionar y desarrollar los tres capiteles esenciales del entrenamiento y la disciplina budistas que son: el comportamiento ético, la disciplina mental, y la sabiduría.

La conducta ética tiene su fundamento en el amor universal y la compasión hacia la humanidad, y es el pilar básico de la enseñanza budista. Y consta de tres factores del Noble Sendero Octuple: recta acción, rectas formas de vida y rectas palabras.

15 Dhammapada, 60.

16 Dhikkuhu BodHI, La Esencia del Budismo. El Noble Sendero Octuple, Edaf, Madrid, 1992, pảg. 27. 
La recta acción significa evitar las conductas negativas que utilizan el cuerpo como medio de exprexión. El Buda hace referencia a tres elementos de la Recta Acción: abstenerse de tomar aquello que no se ha entregado, abstenerse de quitar la vida y evitar el comportamieto sexual inadecuado.

Los rectos medios de vida presuponen que hay que ganarse la vida honradamente. El Buda se refiere a varios tipos de sustentamiento que pueden ser nocivos para otros'seres vivientes y por tanto deben evitarse: el comercio de armas, de vidas humanas, de seres vivos y de venenos. También se mencionan algunos sistemas poco honestos de obtener riqueza: fraudes, estafas, etc.

Rectas palabras significa abstenerse de mentir, chismorrear, charlas frívolas y groserías.

El grupo de la disciplina mental, está compuesto por el recto esfuerzo, la recta atención y la recta concentración.

El recto esfuerzo consiste en: impedir el surgimiento de estados nocivos que no hayan emergido todavía, apartar los estados perjudiciales que hayan aparecido, promover los estados beneficiosos que no se han suscitado aún y desarrollar los estados beneficiosos que ya hayan emergido.

La recta atención se refiere a: prestar atención al cuerpo, a las sensaciones, a los estados y actividades mentales y a los fenómenos.

El octavo factor del sendero es La Recta Concentración que conduce a las cuatro fases de dyāna o absorción.

Finalmente, el grupo de la sabiduría incluye la recta comprensión y el recto pensamiento. La primera consiste en entender la vida tal y como es en realidad. Para ello, es necesario captar de forma clara las Cuatro Verdades Nobles. El recto pensamiento significa pensamientos de renuncia, de amor, de no violencia y de desapego, los cuales son propagados hacia todos los seres vivos ${ }^{17}$.

Este Noble Octuple Camino o Camino del Medio no es ni un camino metafísico ni un camino ritualista; ni dogmatismo ni escepticismo; ni autoindulgencia ni automortificación; ni eternalismo ni nihilismo; ni pesimismo ni optimismo; y no es ni absolutamente de este mundo ni del otro mundo. No es ni pesimismo ni optimismo, sino realismo. Es una vía de iluminación, un medio de liberación del sufrimiento.

\footnotetext{
Sobre el sendero de la iluminación, véase SANGHARAKSHITA, El sendero del Buda. Las Ocho Etapas de la Liberación, Dharma, Novelda (Alicante), 1987. Bhikkhu BoDdHI, ob. cit.
} 
El Budismo no intenta racionalizar el sufrimiento, pero lo acepta como un hecho y trata de hallar la causa, para eliminarlo.

Con una confianza perfecta, los budistas siguen esta senda única de vida practicada y enseñada por el Buda, para obtener su meta final, Nirvāna, que se puede alcanzar en esta vida misma.

Desde el punto de vista ético, Nirvāna es la total destrucción del apego, la malevolencia y la ignorancia. Psicológicamente, es la total eliminación del denominado "Yo» o egoísmo; metafísicamente, es la cesación del devenir o la aniquilación del sufrimiento.

En general, la doctrina budista implicaba «un cambio de método»: enseñó una manera distinta de vivir, rehusándose a detenerse en argumentos sobre dos cuestiones: aquellas no susceptibles de solución por parte del intelecto y las que no eran según el Buda vitalmente centrales sino episódicas.

Respecto al ser humano, el Budismo postula que es una adición de rasgos, o mejor dicho, un fluir de acontecimientos. La realidad del hombre en un instante concreto es una mera colección de elementos (dharmas), varios procesos psíquicos que por lo común se organizan bajo cinco encabezamientos fundamentales: la forma, los sentimientos, las percepciones, los impulsos y la conciencia. La única totalidad que el Budismo contempla es la del universo o quizá, la totalidad de la experiencia de un hombre en un instante concreto, siempre que dicha experiencia no esté oculta por el concepto de que es una entidad continua la que lleva a cabo la experiencia.

Esta concepción, la parte más radical de la doctrina budista y la más nuclear, apareció como respuesta a la concepción hindú del ātman. El Budismo dice: «anātman», no ātman, sin alma, sin sí-mismo, sin «yo» a descubrir.

La doctrina del no-yo como idea filosófica ha seducido a hombres y mujeres durante siglos, y a lo largo de ese tiempo se lo ha polemizado y tergiversado mucho. Sin embargo el budismo no es solamente un sistema filosófico. Su reto no reside en demostrar su idea en un plano intelectual sino, por el contrario, en proponer experimentarla.

Las otras nociones fundamentaies que se consideran imprescindibles para llegar a un determinado conocimiento del pensamiento budista son la compasión (karuna) y la vacuidad (shünyata).

Hace más de dos mil quinientos años el Buda trató de orientar a los hombres hacia un conocimiento más esclarecedor de su propia constitución 
y capacidades psicológicas. Para el Buda, el destino del hombre no está condicionado por ningún tipo de deidad omnisciente que existe más allá de los confines de un mundo «malo». Por el contrario, yace en el poder de aspiración de cada hombre; poder obtenido por el entendimiento y sobre todo, por la práctica traducida en términos de voluntad, disposición y esfuerzo personal.

\section{BIBLIOGRAFIA}

Arnold, E.; La Luz de Asia. El poema del Buda, Teorema, Barcelona, 1984.

BodDHI, Bhikkhu; La Esencia del Budismo. El Noble Sendero Octuple, Edaf, Madrid, 1992.

CARUS, P.; El evangelio de Buda. Unilibro S.A. Barcelona, 1978.

CONZE, E.; Breve Historia del Budismo, Alianza Editorial, Madrid, 1988.

DHAMMAPADA; La senda de la verdad, trad. L. Bassi, Betiles, Buenos Aires, 1979.

IKEDA, Daisaku; Budismo, Primer Milenio, Taurus, Madrid, 1988.

LuBAC, Henri de; La Rencontre du Bouddhisme et de L'Occident, Aubier, Paris, 1952.

RIVIERE, Jean; El yoga tántrico, Kier, Buenos Aires, 1978.

ROMÁN LóPEZ, M. Teresa: Análisis del problema de la conciencia en el Prajñā Pāramitā Hridaya Sütra. Tesis Doctoral. UNED 1994.

RuY, R.A.; El Libro de la Gran Extinción de Gotama el Buddha o sea el Mahā Parinibbāna Suttanta del Digha Nikäya, Hachette, Buenos Aires, 1975.

Sangharakshita; El sendero del Buda. Las Ocho Etapas de la Liberación, Dharma, Novelda (Alicante), 1987.

TSultrim, Ven. Geshe Lobsang; El Adiestramiento Mental y los Doce Vínculos de Originación Interdependiente, Dharma, Novelda (Alicante), 1985.

WAdDELL, L. Austine; The Buddhism of Tibet or Lamaism, Asian Educational Services, New Delhi, 1991.

WolPIN, S.; El Sutra de Benarés. Primer Sermón de Buda, Ibis, Barcelona, 1988.

YosHINORI, T.; The Heart of Buddhism, The Crossroad Publishing Company, New York, 1983. 


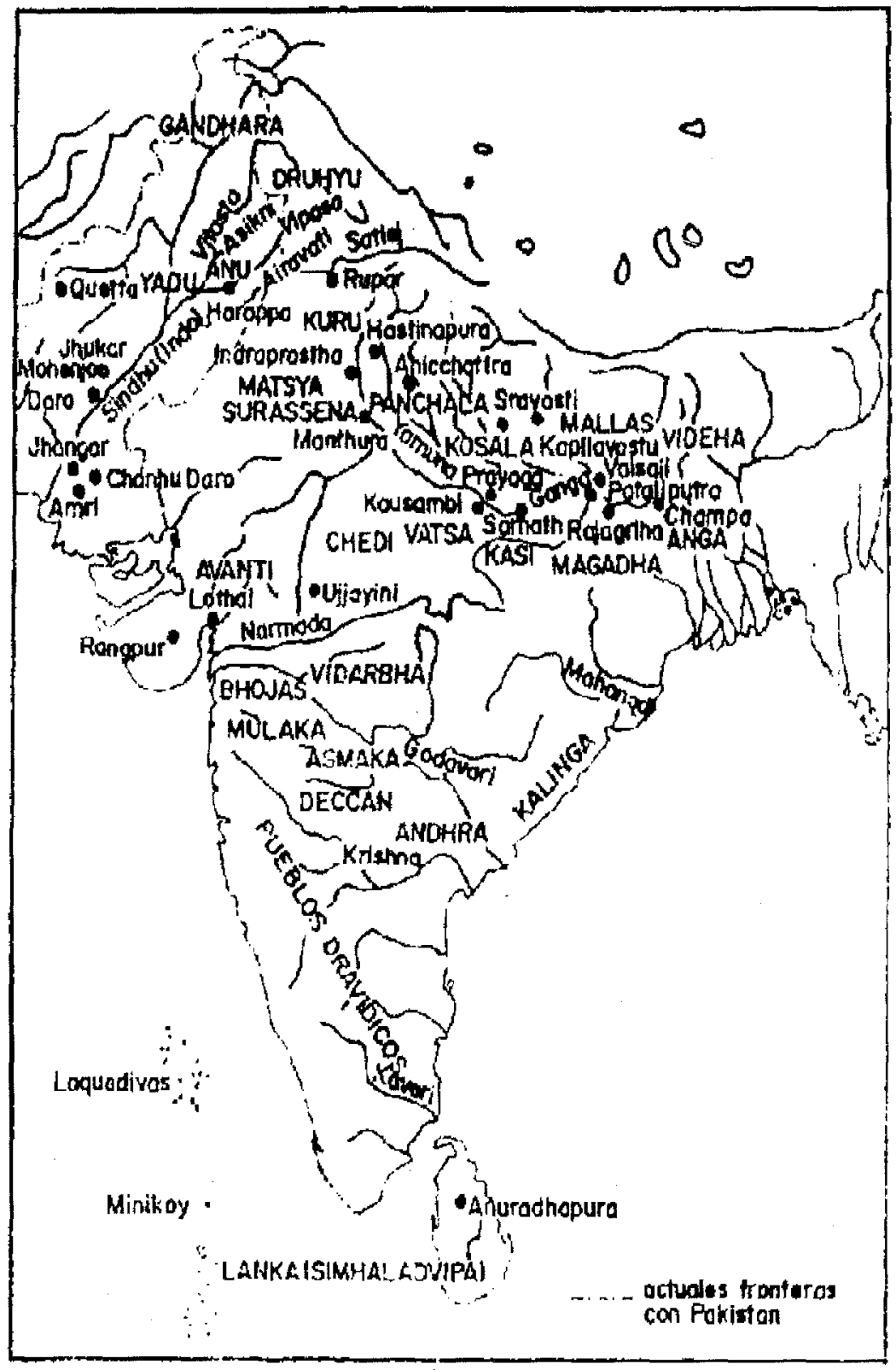

Figura 1. La India antigua antes de los maurya. 


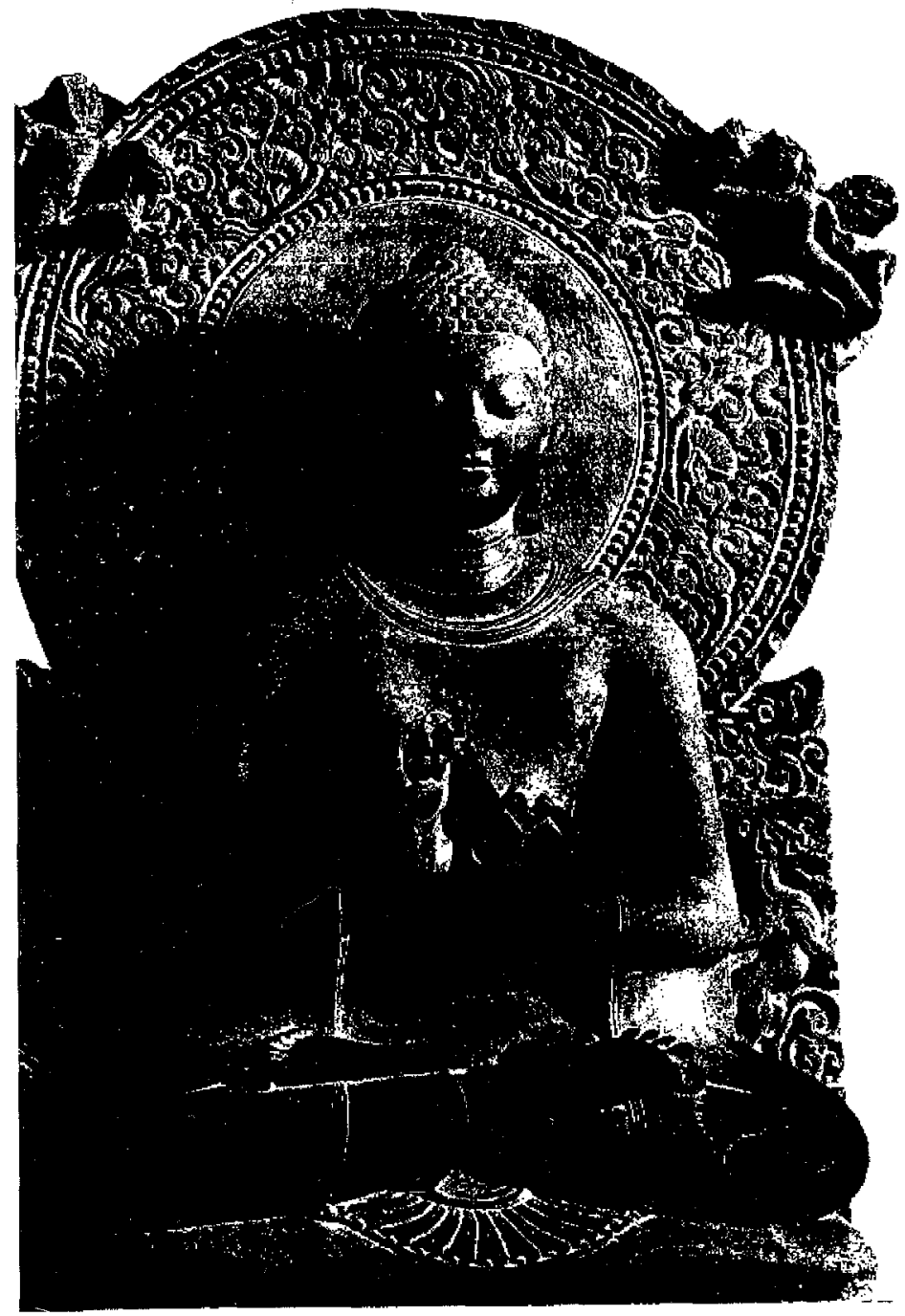

Figura 2. Buda en el acto de pronunciar su primer sermón en el Parque de los Ciervos de Sarnath, arte gupta del siglo v (Sarnath, Museo Arqueológico). La posición de las manos es la llamada dharma cakra, es decir, en el acto de "poner en movimiento la Rueda de la Ley". 